\title{
Opportunistic mammography screening by the Brazilian Unified Health System in 2019
}

\author{
Ruffo Freitas-Junior ${ }^{1,2 *}$ (1), Danielle Cristina Netto Rodrigues ${ }^{1,2}$ (1),

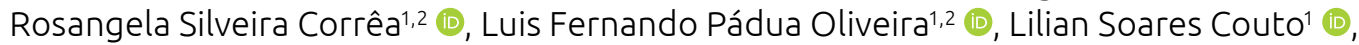 \\ Linei Augusta Brolini Dellê Urban³ (D), Rosemar Macedo Sousa Rahal ${ }^{1,2}$ (D)
}

\section{ABSTRACT}

Introduction: Mammography screening has been the best method for detecting early tumors and reducing breast cancer mortality according to different studies. In Brazil, the number of women who undergo mammography tests by the Brazilian Unified Health System (SUS) has been far below international recommendations. Objective: To describe the number of mammographies, mammography coverage, and the amount spent on this exam during 2019 by SUS, in Brazil. Method: Ecological study with data from the Department of Informatics of the Brazilian Unified Health System and the Brazilian Institute for Geography and Statistics in order to verify the number of mammographies performed by the SUS concerning the Brazilian female population in Brazil, in the age group of 50 to 69 years, in the states and in macro-regions during 2019. Results: In 2019, 2,660,469 mammographies were performed in the country out of the expected total of 12,154,979, accounting for a $21.9 \%$ mammography coverage by SUS at the cost of BRL 117,841,231.97. The lowest coverage rates were verified in the states of Amapá (0.6\%) and the Federal District (4.9\%), whereas the best rates were found in the states of Paraná (29.7\%) and Alagoas (29.6\%). Conclusions: The number of mammographies performed in Brazil in 2019 by SUS corresponded to almost $1 / 4$ of the country's need, with mammography coverage far below the target and being widely different among the many Brazilian states.

KEYWORDS: breast neoplasms; mass screening; mammography; Brazilian Unified Health System; Brazil.

\section{INTRODUCTION}

Mammography has been the most appropriate method for screening breast cancer to date, consisting in the only method that has shown a reduction in mortality from breast neoplasm ${ }^{1}$, reduction in tumor size at diagnosis, and increased survival in patients who developed this type of cancer $^{2}$. However, despite all the benefits, there are several criticisms regarding this method. Among them, we can mention: the non-reduction in the rate of cases of de novo stage IV breast cancer, the increase in detected cases that would not require treatment, in addition to the possibility of an increase in the number of cases of radiation-induced cancer ${ }^{3,4}$.

Despite this worldwide discussion, the impossibility of detecting more aggressive tumors, including cases of interval cancer ${ }^{5}$, together with the great difficulty of access to health services that exists in Brazil ${ }^{6}$, certainly makes the model of opportunistic breast cancer screening to not be fully adopted in the country yet, with an effective reduction in mortality, as previously published ${ }^{7,8}$.

In a recent study conducted by the Rede Brasileira de Pesquisa em Câncer de Mama [Brazilian Breast Cancer Research Network], following the recommendations of the Brazilian Ministry of Health, according to which women aged between 50 and 69 years must undergo a biennial mammography examination, it was observed that the rate of mammography coverage by the Brazilian Unified Health System (SUS) in this population increased from $14.4 \%$ in 2008 to $24.4 \%$ in 2012 and, since then, mammography coverage has been stabilized, accounting for $24.2 \%$ in $2017^{9}$.

These numbers must be updated for 2019 and, therefore, the objective of this study was to analyze data from the Department of Informatics of the Brazilian Unified Health System (DATASUS) for the year 2019, considering, in addition to the absolute number of mammographies, the mammography coverage and the amount spent by SUS on these exams in 2019 .

${ }^{1}$ Breast Cancer Program, Hospital das Clínicas, Universidade Federal de Goiás - Goiânia (GO), Brazil.

Brazilian Breast Cancer Research Network - Goiânia (GO), Brazil.

${ }^{3}$ National Mammography Commission, Colégio Brasileiro de Radiologia - São Paulo (SP), Brazil.

*Corresponding author: ruffojr@terra.com.br

Conflict of interest: nothing to declare.

Received on: 05/04/2020. Accepted on: 06/01/2020. 


\section{METHODS}

\section{Study design}

This is an ecological, descriptive study, with secondary data from the Brazilian Ambulatory Information System (SIA/DATASUS) and the Brazilian Institute for Geography and Statistics (IBGE) for 2019.

\section{Target population}

Women aged 50 to 69 years were considered the target population. Data on the number of surveyed women for the period from January 1 to December 31, 2019 were collected from SIA/ DATASUS $^{10}$. The IBGE projection of the Brazilian population for the year 2019 was considered ${ }^{11}$.

\section{Coverage estimates}

Mammography coverage was estimated considering the biennial screening in order to reach $100 \%$ of the target population. It was expressed as percentage and calculated using the ratio between the number of performed tests and the number of expected tests.

Data on the number of tests performed from January 1 to December 31, 2019 were collected from SIA/DATASUS, according to procedure codes 0204030030 (Mammography) and 0204030188 (Bilateral Mammography for Screening).

To estimate the number of tests expected in the population aged 50 to 69 years, the recommendation of the National Cancer Institute José Alencar Gomes da Silva (INCA) was adopted. In scheduling procedures, it is necessary to predict that, in a given year, $50 \%$ of women aged 50 to 69 years shall undergo screening through clinical breast exam, in addition to a diagnostic mammography in $8.9 \%$ of this population, who will have an altered clinical breast exam; while the other $50 \%$ of women shall undergo a clinical breast exam and mammography screening, regardless of the result in the clinical breast exam ${ }^{12}$.

\section{RESULTS}

According to data collected from SIA/DATASUS, in 2019 a total of 2,660,469 mammographies were performed in the country out of the expected total of 12,154,979, accounting for a $21.9 \%$ mammography coverage by SUS at the cost of BRL 117,841,231.97, as demonstrated in Table 1. Each of the values was repeated for the Brazilian states, the Federal District, and the country's macro-regions.

\section{DISCUSSION}

In addition to the current model of mammography screening used worldwide, performed by mammography and complemented by other exams, including breast ultrasound and breast magnetic resonance imaging, in cases of high-risk patients ${ }^{1,2,13}$, we observed that some situations must be remedied if the current model prevails. The first one involves remedying the low productivity of mammography machines available at SUS. In a recent study conducted by the Brazilian Breast Cancer Research Network, the extremely low productivity of the machines was observed, which shows that, in the country, there is no lack of mammography equipment, but rather of an efficient operation in all states, considering that the effectiveness ranged between $1 \%$ in the Federal District to $40 \%$ in the state of Bahia ${ }^{14}$. These numbers evidence the urgent need to reorganize several services related to SUS, which alone can promote a considerable improvement in mammography coverage for SUS users.

Another aspect that must be addressed is the issue of bureaucracy in undergoing the mammography test by SUS. In places where there is an organized population screening, women in the age group in question receive an invitation letter to do the mammography, and that is enough for them to undergo the exam. Then, the test result is evaluated by a doctor and they receive a new letter informing the result and already scheduling a new exam for the next round of tests, as recommended in different countries ${ }^{1,5,15}$.In Brazil, despite financial and time-related difficulties existing among the population served at SUS, women must first have a medical prescription for undergoing a mammography, which is usually prescribed by doctors working in Health Units or, eventually, in the Family Health Strategy program, which is a Brazilian program aiming at reorganizing primary healthcare services, promoting the quality of life of the Brazilian population, and preventing factors that pose risk to their health. Then, they must go to a location selected by the Brazilian Department of Health to get an authorization for undergoing procedures of low-to-medium complexity, and only then they shall schedule the mammography. Another time, these women will spend more time undergoing the exam. As if that were not enough, they must get the test result and then take it to a doctor. Only based on the exam the professional can reassure them or, when necessary, request some complementary exam such as imaging tests or even biopsy.

In Flanders, Belgium, for women aged between 50 and 69 years, the debureaucratization and change from an opportunistic screening to an organized, biennial screening model increased mammography coverage from $14 \%$, in 2002 , to $64 \%$, in $2016^{5}$. This indicates that such organized and unbureaucratic model may be a good option for the Brazilian public health.

The clear need for improving the quality of the exams itself cannot be disregarded. Accordingly, the increase in radiation levels and the patient's poor positioning on the mammography machine are factors that have been observed and that, among others, may generate the poor quality of the mammography, increasing the possibility of false-negative mammograms, as well as false-positive ones, and further reducing the accuracy of the exam in its general context ${ }^{16,17}$.

Concerning the mammography coverage, the year 2019 reflects what happened in the previous years, from 2012 to $2017^{9}$, when there was no increase in mammography coverage in the female population aged 50 to 69 years who use the SUS services. This probably reflects a political issue, with greater emphasis on the economic and financial situation in which Brazil was immersed in the period under analysis. 
Table 1. Resident population, number of tests expected and performed, mammography coverage, and value approved by the Brazilian Unified Health System (SUS), in Brazil and in the states, in 2019.

\begin{tabular}{|c|c|c|c|c|c|}
\hline $\begin{array}{l}\text { Federation Unit / } \\
\text { Macro-region }\end{array}$ & $\begin{array}{l}\text { Resident } \\
\text { population }\end{array}$ & $\begin{array}{l}\text { No. of expected } \\
\text { tests }\end{array}$ & $\begin{array}{l}\text { No. of performed } \\
\text { tests }\end{array}$ & Coverage & $\begin{array}{c}\text { Approved value in } \\
\text { Brazilian currency (BRL) }\end{array}$ \\
\hline Rondônia & 142,254 & 83,788 & 7,053 & 8.4 & $282,271.40$ \\
\hline Acre & 50,350 & 29,656 & 4,983 & 16.8 & $216,135.00$ \\
\hline Amazonas & 251,965 & 148,407 & 20,233 & 13.6 & $903,645.20$ \\
\hline Roraima & 31,838 & 18,753 & 2,544 & 13.6 & $112,270.40$ \\
\hline Pará & 569,845 & 335,639 & 28,818 & 8.6 & $1,272,678.90$ \\
\hline Amapá & 45,579 & 26,846 & 149 & 0.6 & $6,230.20$ \\
\hline Tocantins & 114,284 & 67,313 & 5,899 & 8.8 & $256,145.50$ \\
\hline North Region & $1,206,115$ & 710,402 & 69,679 & 9.8 & $3,049,376.60$ \\
\hline Maranhão & 486,906 & 286,788 & 25,127 & 8.8 & $1,101,064.05$ \\
\hline Piauí & 286,053 & 168,485 & 39,231 & 23.3 & $1,891,496.80$ \\
\hline Ceará & 797,849 & 469,933 & 53,040 & 11.3 & $2,337,265.40$ \\
\hline Rio Grande do Norte & 321,350 & 189,275 & 34,222 & 18.1 & $1,705,435.60$ \\
\hline Paraíba & 370,021 & 217,942 & 37,873 & 17.4 & $1,697,252.30$ \\
\hline Pernambuco & 885,113 & 521,332 & 129,864 & 24.9 & $5,743,554.65$ \\
\hline Alagoas & 279,667 & 164,724 & 48,723 & 29.6 & $2,185,020.40$ \\
\hline Sergipe & 195,138 & 114,936 & 22,847 & 19.9 & $1,023,714.80$ \\
\hline Bahia & $1,253,851$ & 738,518 & 207,571 & 28.1 & $10,703,861.41$ \\
\hline Northeast Region & $4,981,403$ & $2,934,046$ & 598,498 & 20.4 & $28,388,665.41$ \\
\hline Minas Gerais & $2,233,182$ & $1,315,344$ & 311,008 & 23.6 & $13,363,522.17$ \\
\hline Espírito Santo & 406,091 & 239,188 & 58,817 & 24.6 & $2,571,096.00$ \\
\hline Rio de Janeiro & $1,987,179$ & $1,170,448$ & 170,219 & 14.5 & $7,338,582.60$ \\
\hline São Paulo & $4,982,976$ & $2,934,973$ & 817,050 & 27.8 & $35,369,659.45$ \\
\hline Southeast Region & $9,609,428$ & $5,659,953$ & $1,357,094$ & 24.0 & $58,642,860.22$ \\
\hline Paraná & $1,233,399$ & 726,472 & 215,671 & 29.7 & $9,483,834.50$ \\
\hline Santa Catarina & 751,272 & 442,499 & 101,027 & 22.8 & $4,392,800.90$ \\
\hline Rio Grande do Sul & $1,369,087$ & 806,392 & 212,135 & 26.3 & $9,232,842.64$ \\
\hline South Region & $3,353,758$ & $1,975,363$ & 528,833 & 26.8 & $23,109,478.04$ \\
\hline Mato Grosso do Sul & 258,313 & 152,146 & 28,194 & 18.5 & $1,207,360.50$ \\
\hline Mato Grosso & 287,850 & 169,544 & 19,025 & 11.2 & $841,474.00$ \\
\hline Goiás & 644,129 & 379,392 & 50,684 & 13.4 & $2,230,190.10$ \\
\hline Federal District & 295,640 & 174,132 & 8,462 & 4.9 & $371,827.10$ \\
\hline Midwest Region & $1,485,932$ & 875,214 & 106,365 & 12.2 & $4,650,851.70$ \\
\hline Brazil & $20,636,636$ & $12,154,979$ & $2,660,469$ & 21.9 & $117,841,231.97$ \\
\hline
\end{tabular}

Hence, the year 2019 clearly indicates the need for greater allocation of financial and, mainly, organizational resources, in order to increase the number of mammographies performed in the country. This adjustment should include the reduction in the existing bureaucracy for undergoing the exam, as well as the improvement in the promptness of each step, in such a way that women do not waste time with so many steps and can access the diagnosis quickly and effectively.

\section{AUTHORS' CONTRIBUTION}

R.F.-J., D.C.N.R., R.S.C., L.F.P.C., L.S.C., L.A.B.D.U., R.M.S.R.: Concept, research, methodology.

R.F.-J., D.C.N.R.: Data processing, formal analysis, writing of the article and its first version.

R.S.C., L.F.P.C., L.S.C., L.A.B.D.U., R.M.S.R.: Data validation, methodology review, writing review and editing.

R.F.-J., D.C.N.R., R.S.C., L.F.P.C., L.S.C., L.A.B.D.U., R.M.S.R.: Review and approval of the final version. 


\section{REFERENCES}

1. Dibden A, Offman J, Duffy SW, Gabe R. Worldwide Review and Meta-Analysis of Cohort Studies Measuring the Effect of Mammography Screening Programmes on Incidence-Based Breast Cancer Mortality. Cancers. 2020;12(4):976. http://doi. org/10.3390/cancers12040976

2. Gøtzsche PC, Jørgensen KJ. Screening for breast cancer with mammography. Cochrane Database Syst Rev. 2013;6:CD001877. http://doi.org/10.1002/14651858.CD001877.pub5

3. Dos-Santos-Silva I, De Stavola BL, Renna-Junior NL, Nogueira MC, Aquino EML, Bustamante-Teixeira MT, et al. Ethnoracial and social trends in breast cancer staging at diagnosis in Brazil, 200114: a case only analysis. Lancet Glob Health. 2019;7(6):e784-e797. https://doi.org/10.1016/s2214-109x(19)30151-2

4. Pauwels EK, Foray N, Bourguignon MH. Breast Cancer Induced by X-Ray Mammography Screening? A Review Based on Recent Understanding of Low-Dose Radiobiology. Med Princ Pract. 2016;25(2):101-9. https://doi.org/10.1159/000442442

5. Goossens M, De Brabander I, De Grève J, Van Ongeval C, Martens P, Van Limbergen E, et al. BMC Cancer. Flemish breast cancer screening programme: 15 years of key performance indicators (2002-2016). 2019;19:1012. https://doi.org/10.1186/ s12885-019-6230-z

6. Freitas-Junior R, Rodrigues DCN, Corrêa RS, Peixoto JE, Oliveira HVCG, Rahal RMS. Contribution of the Unified Health Care System to mammography screening in Brazil, 2013. Radiol Bras. 2016;49(5):305-10. https://doi.org/10.1590/0100-3984.2014.0129

7. Gonzaga CMR, Freitas-Junior R, Souza MR, Curado MP, Freitas NMA. Disparities in female breast cancer mortality rates between urban centers and rural areas of Brazil: Ecological time-series study. Breast. 2014;23(2):180-7. https:// doi.org/10.1016/j.breast.2014.01.006

8. Gonzaga CMR, Freitas-Junior R, Curado MP, Sousa ALL, Souza-Neto JA, Souza MR. Temporal trends in female breast cancer mortality in Brazil and correlations with social inequalities: ecological time-series study. BMC Public Health. 2015;15:96. https://doi.org/10.1186/s12889-015-1445-7

9. Rodrigues DCN, Freitas-Junior R, Rahal RMS, Silveira Corrêa R, Gouveia PA, Peixoto JE, et al. Temporal changes in breast cancer screening coverage provided under the Brazilian National Health Service between 2008 and 2017. BMC Public Health. 2019;19(1):959. https://doi.org/10.1186/s12889-019-7278-z
10. Brasil. Ministério da Saúde. Departamento de Informática do SUS - DATASUS. Informações de Saúde (TABNET). Demográficas e Socioeconômicas [Internet]. Brasília: Ministério da Saúde; 2019 [acessed on Apr. 14, 2019]. Available at: http:// tabnet.datasus.gov.br/cgi/deftohtm.exe?ibge/cnv/popuf.def

11. Brasil. Instituto Brasileiro de Geografia e Estatística. Diretoria de Pesquisas. Coordenação de População e Indicadores Sociais. Gerência de Estudos e Análises da Dinâmica Demográfica. Projeção da população do Brasil e Unidades da Federação por sexo e idade para o período 2000-2030 [Internet]. Brasília: Ministério da Saúde [acessed on Apr. 14, 2019]. Available at: http://www.ibge.gov.br/home/estatística/população/

12. Brasil. Ministério da Saúde. Parâmetros técnicos para o rastreamento do câncer de mama: recomendações para gestores estaduais e municipais [Internet]. Rio de Janeiro: INCA; 2009 [acessed on Apr. 30, 2019]. Available at: http://bvsms.saude.gov.br/ bvs/publicacoes/parametros_rastreamento_cancer_mama.pdf

13. Urban LABD, Chala LF, Bauab SDP, Schaefer MB, Dos Santos RP, Maranhão NMA, et al. Breast cancer screening: updated recommendations of the Brazilian College of Radiology and Diagnostic Imaging, Brazilian Breast Disease Society, and Brazilian Federation of Gynecological and Obstetrical Associations. Radiol Bras. 2017;50(4):244-9. https://doi.org/10.1590/0100-3984.2017-0069

14. Rodrigues DCN, Freitas-Junior R, Rahal RMS, Correa RS, Peixoto JE, Ribeiro NV, et al. Difficult Access and Poor Productivity: Mammography Screening in Brazil Asian Pac J Cancer Prev. 2019;20(6):1857-64. https://doi.org/10.31557/apjcp.2019.20.6.1857

15. Moss SM, Wale C, Smith R, Evans A, Cuckle H, Duff SW. Effect of mammographic screening from age 40 years on breast cancer mortality in the UK Age trial at 17 years' follow-up: a randomised controlled trial. Lancet Oncol. 2015;16(9):1123-32. https://doi.org/10.1016/s1470-2045(15)00128-x

16. Corrêa RS, Freitas-Junior R, Peixoto JE, Netto-Rodrigues DC, Lemos MEF, Dias CM, et al. Effectiveness of a quality control program in mammography for the Brazilian National Health System. Rev Saúde Pública. 2012;46(5):769-76. http://dx.doi. org/10.1590/S0034-89102012000500002

17. Soares LR, Rahal RMS, Queiroz VCJ, Aquino EC, Correa RS, Rodrigues DCN, et al. Clinical quality Control of mammograms evaluated in aBraziliantertiaryHospital.Mastology.2018;28(Suppl. 1):6. http://dx.doi.org/10.29289/259453942018V28S1008 